\title{
ТРЕБОВАНИЯ К РАЗРАБОТКЕ ПРОГРАММНОГО ОБЕСПЕЧЕНИЯ ДИСТАНЦИОННОГО БАНКОВСКОГО ОБСЛУЖИВАНИЯ
}

\author{
Доцент, к.т.н., и.о. зав. Кафедрой О. Н. Образцова \\ Старший преподаватель, иссл.т.н. О. М. Бакунова \\ Студент А. А. Гуринович \\ Студент Р. В. Левщунов \\ Студент С. В. Павлов \\ Студент В. Д. Дивин \\ Студент И. А. Шуба \\ Студент В. М. Светличный
}

Беларусь, Минск, Белорусский государственный университет информатики и радиоэлектроники, кафедра информационных систем и технологий

DOI: https://doi.org/10.31435/rsglobal_wos/30062019/6549

\section{ARTICLE INFO}

Received: 27 April 2019

Accepted: 20 June 2019

Published: 30 June 2019

\section{KEYWORDS}

automation,

banking,

remote banking service.

\begin{abstract}
The article discusses the benefits of implementing remote banking services, formulated the diverse requirements for remote banking software, in particular, requirements in terms of integration with banking systems, in terms of security and in terms of usability. Considering these requirements allows us to formulate a high-quality technical task for the development of software for remote banking services.
\end{abstract}

Citation: О. Н. Образцова, О. М. Бакунова, А. А. Гуринович, Р. В. Левшунов, С. В. Павлов, В. Д. Дивин, И. А. Шуба, В. М. Светличный. (2019) Requirements for the Development of Remote Banking Services Software. International Academy Journal Web of Scholar. 6(36). doi: 10.31435/rsglobal_wos/30062019/6549

Copyright: (C 2019 О. Н. Образцова, О. М. Бакунова, А. А. Гуринович, Р. В. Левшунов, С. В. Павлов, В. Д. Дивин, И. А. Шуба, В. М. Светличный. This is an open-access article distributed under the terms of the Creative Commons Attribution License (CC BY). The use, distribution or reproduction in other forums is permitted, provided the original author(s) or licensor are credited and that the original publication in this journal is cited, in accordance with accepted academic practice. No use, distribution or reproduction is permitted which does not comply with these terms.

Введение. Современная банковская система - это сфера многообразных услуг, предоставляемых клиентам - от традиционных денежно-ссудных и расчетно-кассовых операций, определяющих основу банковского дела, до новейших форм денежно кредитных и финансовых инструментов, используемых банковскими структурами (лизинг, факторинг и т.д.).

Банковская деятельность - это та сфера, которая внедряет новые компьютерные технологии одной их первых. [1] Почти все задачи, которые возникают в ходе работы банка, достаточно легко поддаются автоматизации. Быстрая и бесперебойная обработка значительных потоков информации является одной из главных задач любой крупной финансовой организации. В соответствии с этим очевидна необходимость обладания вычислительной сетью, позволяющей обрабатывать все возрастающие информационные потоки [2]. Кроме того, именно банки обладают достаточными финансовыми возможностями для использования самой современной техники. В соответствии с общемировой практикой в среднем банке расходы на компьютеризацию составляют не менее $17 \%$ от общей сметы годовых расходов.

Интерес к развитию компьютеризированных банковских систем определяется главным образом, стратегическими интересами. Как показывает практика, инвестиции в такие проекты 
начинают приносить прибыль лишь через определенный период времени, необходимый для обучения персонала и адаптации системы к конкретным условиям. Вкладывая средства в программное обеспечение, компьютерное и телекоммуникационное оборудование и создание базы для перехода к новым вычислительным платформам, банки, в первую очередь, стремятся к удешевлению и ускорению своей рутинной работы и победе в конкурентной борьбе.

Дистанционное банковское обслуживание (ДБО) - это комплекс услуг удаленного доступа к разным банковским операциям, которые банки предлагают своим клиентам (как юридическим, так и физическим лицам). Используя услуги ДБО, клиенты могут, совершать удаленный доступ к своим счетам в банке или производить платежи и переводы при помощи разных технических средств, каналов связи и с применением специализированных программных продуктов. Подобная форма взаимодействия с банком позволяет клиентам принимать актуальную информацию из банка или отдавать банку свои команды в нужное время без визита в банк.

Под услугами дистанционного банковского обслуживания понимаются разные электронные услуги, разрешающие обслуживать клиентов с применением всех каналов доступа: Интернет (on-line и off-line доступ), телефон, планшет, платежные терминалы и другие.

Результаты и обсуждение. Рассмотрим преимущества и недостатки внедрения ДБО, и вытекающие из них требования, предъявляемые к программному обеспечению для ДБО.

Использование дистанционных банковских услуг через Интернет представляет собой одну из самых перспективных и быстро развивающихся областей. Быстрое развитие информационных технологий привело к тому, что Интернет начал применяться не только как средство для размещения всеобщей информации о банках и их продуктах, но и как сеть, посредством которой банки могут предоставить клиентам возможность выполнения огромного спектра информационных запросов и активных операций (платежей, переводов и т.д.).

Основные преимущества дистанционного банковского обслуживания для клиента:

- удобство - клиент всегда может использовать услуги из любой точки земного шара;

- оперативность - оплата услуг с помощью систем дистанционного обслуживания происходит с большой скоростью, в некоторых случаях мгновенно;

- доступность - стоимость использования услуг удаленного обслуживания невелика, часто банки предлагают свои услуги ДБО бесплатно;

- выгодность - часто банки предоставляют клиенту возможность выполнения удаленных банковских операций по более выгодным тарифам чем, если клиент будет обслуживаться в офисе;

- разнообразие - многие банки поддерживают и развивают разные каналы дистанционного обслуживания (интернет, мобильный или стационарный телефон).

Главные преимущества дистанционного банковского обслуживания для банка:

- Экономическая выгода благодаря сокращению стоимости обслуживания клиента затраты на предоставление услуг клиенту в отделениях банка и точках продаж значительно выше, чем при удаленном взаимодействии. Безусловно, банк несет немалые расходы, чтобы внедрить системы ДБО, но они всегда окупаются через определенный период времени и, чем больше клиентов банк подключает к удаленным сервисам, тем быстрее заканчивается период окупаемости затрат.

- Удаленное обслуживание, к которому также можно отнести и обслуживание клиентов с помощью терминалов и устройств самообслуживания гораздо эффективнее, если его сравнить с традиционным обслуживанием в офисе банка, т.к. ни один банк не в состоянии обслужить в своих офисах десятки тысяч клиентов. В результате сокращения времени на взаимодействие с клиентом снижается, а самое главное то, что пропускная способность обслуживания увеличивается. И чем активнее банк работает с частными клиентами, тем больший эффект дает дистанционное обслуживание.

- Внедрение дистанционного обслуживания поможет решить задачи развития точек присутствия и обеспечит доступность для клиента услуг банка в любом удобном месте и в любое удобное время.

- Возникают возможности привлечения клиентов вне зависимости от их географического местонахождения, банк получает выход на новые клиентские сегменты, которые банк не мог обслуживать до внедрения удаленных сервисов. 
- Увеличивается скорость и повышается качество обслуживания клиентов.

- Увеличивается точность производимых банковских операций, уменьшается количество всевозможных ошибок, снижаются операционные риски банка.

- У банка появляются возможности для решения важных дополнительных задач, к примеру, предоставлять клиенту оперативную информацию о новых банковских продуктах или сообщать клиенту о необходимых действиях (своевременном погашении просрочки, окончании срока депозита и т.п.).

- Увеличивается уровень конкурентоспособности банка благодаря возможности создания принципиально новых банковских продуктов и быстрого масштабирования и интегрирования банковских услуг с другими финансовыми услугами, использующими удаленный доступ к денежным счетам.

Несмотря на многочисленные преимущества, использование дистанционного банковского обслуживания так же имеет и ряд недостатков. Общий недостаток ДБО обусловлен именно особенностями такого обслуживания, то есть тем, что банковские операции осуществляются клиентом удаленно без непосредственного общения со специалистами банка. Именно из-за этого могут возникнуть проблемы верной идентификации клиента при дистанционном выполнении им банковских операций.

Причем эта проблема существует как для кредитных организаций, так и для клиентов. Для банка особенно важны гарантии того, что удаленные операции выполняются именно тем человеком, которому банк предоставил на это право. Клиент должен быть уверен, что никто кроме него (по злому умыслу или по ошибке) не сможет использовать его счета в банке.

С точки зрения структуры банковских систем, программное обеспечение, разрабатываемое для ДБО, должно учитывать модульность банковских систем, при этом часть модулей банковской системы разрабатывается компьютерным отделом банка, а часть покупается у независимых производителей. Также необходимо предусмотреть возможность интеграции с уже имеющимся программным обеспечением [3] и наличие средств адаптации к конкретным условиям эксплуатации. Для поддержки оперативной работы банка БС должна функционировать в режиме реального времени OLTP (On-line Transaction Processing).

Перечислим основные функции БС (обычно они реализуются в виде независимых модулей единой системы):

1 Автоматизация всех ежедневных внутрибанковских операций, ведение бухгалтерии и составление сводных отчетов.

2 Системы коммуникаций с филиалами и иногородними отделениями.

3 Системы автоматизированного взаимодействия с клиентами (так называемые системы “банк-клиент”).

4 Аналитические системы. Анализ всей деятельности банка и системы выбора оптимальных в данной ситуации решений.

5 Автоматизация розничных операций - применение банкоматов и кредитных карточек.

6 Системы межбанковских расчетов.

7 Системы автоматизации работы банка на рынке ценных бумаг.

8 Информационные системы. Возможность мгновенного получения необходимой информации, влияющей на финансовую ситуацию.

С точки зрения безопасности, программное обеспечение для ДБО может быть оснащено электронной цифровой подписью (ЭЦП). Её применение в качестве средства для идентификации и подтверждения юридической значимости документов становится стандартом цифрового мира.

Использование электронной подписи в Беларуси регламентировано Законом «Об электронном документе и электронной цифровой подписи» [4]. ЭЦП дает право полноценно подписывать электронные документы и обращения, подаваемые в Министерство по налогам и сборам (например, электронные декларации), таможенные органы, фонды соцзащиты населения и др.

Электронная цифровая подпись (ЭЦП) - реквизит электронного документа, предназначенный для удостоверения источника данных и защиты данного электронного документа от подделки. Электронная цифровая подпись представляет собой последовательность символов, полученную в результате криптографического преобразования электронных данных. ЭЦП добавляется к блоку данных и позволяет получателю блока 
проверить источник и целостность данных и защититься от подделки. ЭЦП используется в качестве аналога собственноручной подписи.

При создании ЭЦП печатается карточка открытого ключа. Карточка открытого ключа электронный или бумажный документ, содержащий открытый ключ, информацию о владельце ключа, области применения ключа, подписанный выдавшим его Удостоверяющим центром и подтверждающий принадлежность открытого ключа владельцу. В Республике Беларусь технология ЭЦП создана ЗАО «АВЕСТ». Чтобы подписать документ клиент должен владеть специальной флэшкой, на которой зашифрована его подпись. Данную флэшку может получить только в отделении банка.

Таким образом, электронная цифровая подпись - эффективное средство защиты информации от модификации, искажений, позволяющее при этом однозначно идентифицировать отправителя сообщения и перенести свойства реальной подписи под документом в область электронного документа. Она является наиболее перспективным и широко используемым в мире способом защиты электронных документов от подделки и обеспечивает высокую достоверность сообщения.

С точки зрения разработки пользовательского интерфейса, ДБО является типичной системой «человек-компьютер-среда», поэтому распределение функций между человеком и техническими устройствами осуществляется с учетом следующих принципов:

1 Человек-оператор, воздействуя на техническое звено системы, задаёт настройки системы. Функция передается тому или иному компоненту системы на основе сравнительного анализа человека и техники на предмет возможности и эффективности ее выполнения ими;

2 Человеку также передаются те функции, которые определяются особенностями системы с учетом ее назначения, т.е. за человеком сохраняются функции, которые он должен выполнить в системе обязательно безо всякого дополнительного сравнительного анализа возможностей человека и машины.

3 Рабочая среда рабочего места человека-оператора включает такие факторы, как освещенность, шум, аэроионный состав воздуха, микроклимат, вибрация, электромагнитное излучение. Если не ставится цель изучить работу человека-оператора в экстремальных условиях, то все факторы необходимо привести к оптимальному значению. В иных случаях можно варьировать значения необходимых параметров, не допуская при этом причинения ущерба здоровью, работающего [5].

Распределение функций между человеком и компьютером в проектируемой системе приведено в таблице 1.

Таблица 1.

\begin{tabular}{|l|c|l|}
\hline \multicolumn{1}{|c|}{ Функция } & Кто ее выполняет & Обоснование распределения функций \\
\hline $\begin{array}{l}\text { Ввод регистрационных } \\
\text { данных. }\end{array}$ & Человек & Функция остается за человеком \\
\hline $\begin{array}{l}\text { Сохранение регистрационных } \\
\text { данных. }\end{array}$ & ПК & $\begin{array}{l}\text { Функция ПК, позволяющая сохранять } \\
\text { результаты на длительное время }\end{array}$ \\
\hline $\begin{array}{l}\text { Авторизованный вход в } \\
\text { систему }\end{array}$ & Человек & $\begin{array}{l}\text { Человек-оператор вводит свои личные } \\
\text { данные }\end{array}$ \\
\hline Выбор необходимой функции & Человек & Функция остается за человеком \\
\hline $\begin{array}{l}\text { Предоставление справочной } \\
\text { информации }\end{array}$ & ПК & $\begin{array}{l}\text { ПК выводит на монитор текстовую } \\
\text { информацию }\end{array}$ \\
\hline Отправка платежей в банк & Человек & Функция остается за человеком \\
\hline $\begin{array}{l}\text { Получение выписки по счету } \\
\text { предприятия. }\end{array}$ & $\begin{array}{l}\text { ПК позволяет выводить на дисплей } \\
\text { выписки }\end{array}$ \\
\hline $\begin{array}{l}\text { Формирование отчетов. } \\
\text { ПК }\end{array}$ & $\begin{array}{l}\text { ПК позволяет выводить на дисплей } \\
\text { монитора отчеты }\end{array}$ \\
\hline Прием платежей с банка & $\begin{array}{l}\text { ПК позволяет выводить на дисплей } \\
\text { новые платежи }\end{array}$ \\
\hline
\end{tabular}

Выводы. Рассмотрены разносторонние требования к программному обеспечению дистанционного банковского обслуживания, позволяющие качественно сформулировать техническое задание на разработку подобного программного обеспечения. 


\section{ЛИТЕРАТУРА}

1. Бакунова, О. М., Калитеня, И. Л., Тимофеев, Д. О., Уласович, В. Ю., Ухналев, Р. Ю., Михаленко, В. А. Возможность использования искусственного интеллекта в банковской сфере // Web of Scholar. 2018. - 4(22), Vol.1. - Pp. 13 - 15.

2. Bakunova, O. M., Lisovskiy, A. A., Mazur, A. D., Tsimafeyeu, D. O., Pratsko, D. E., Kaliaha, U. V., Kryzhanouskaya, Y. A. Software tool "FILING CABINETS" // Proceedings of the Second International Conference of European Academy of Science, Bonn, November 20 - 28 2018. - Bonn, 2018. - C. 21 - 22.

3. Бакунова О.М., Калитеня И.Л., Уласович В.Ю., Тимофеев Д.О., Ухналев Р.Ю., Михаленко В.А. Интеграция информационных систем с использованием Mule ESB. Web of Scholar. - 2018. - 4(22), Vol.1. - Pp. 4 - 7.

4. Закон Республики Беларусь от 28.12.2009 № 113-3 «Об электронном документе и электронной цифровой подписи»

5. Хаф, Л. Проектирование информационных систем / Л. Хаф. - М.: Бином, 2016 - 728 с. 